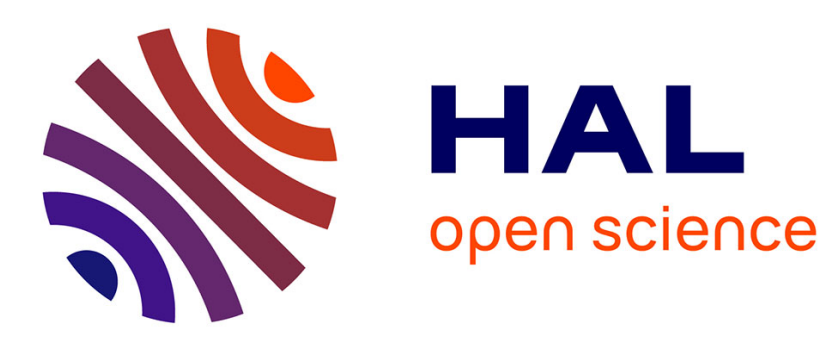

\title{
Feeding of Small Components Using the Surface Tension of Fluids
}

Matthias Burgard, Nabih Othman, Uwe Mai, Dirk Schlenker, Alexander Verl

\section{To cite this version:}

Matthias Burgard, Nabih Othman, Uwe Mai, Dirk Schlenker, Alexander Verl. Feeding of Small Components Using the Surface Tension of Fluids. 7th International Precision Assembly Seminar (IPAS), Feb 2014, Chamonix, France. pp.47-51, 10.1007/978-3-662-45586-9_7 . hal-01260728

\section{HAL Id: hal-01260728 \\ https://inria.hal.science/hal-01260728}

Submitted on 22 Jan 2016

HAL is a multi-disciplinary open access archive for the deposit and dissemination of scientific research documents, whether they are published or not. The documents may come from teaching and research institutions in France or abroad, or from public or private research centers.
L'archive ouverte pluridisciplinaire HAL, est destinée au dépôt et à la diffusion de documents scientifiques de niveau recherche, publiés ou non, émanant des établissements d'enseignement et de recherche français ou étrangers, des laboratoires publics ou privés.

\section{(c)(1)}

Distributed under a Creative Commons Attribution| 4.0 International License 


\title{
Feeding of Small Components Using the Surface Tension of Fluids
}

\author{
Matthias Burgard, Nabih Othman, Uwe Mai, Dirk Schlenker, Alexander Verl \\ Fraunhofer Institute for Manufacturing Engineering and Automation IPA, Stuttgart, Germany \\ \{matthias.burgard, nabih.othman, uwe.mai\}eipa.fraunhofer.de \\ Fraunhofer IPA \\ Matthias Burgard \\ Nobelstr. 12 \\ 70569 Stuttgart \\ GERMANY \\ Phone: +49-711-970 1105 \\ Fax: +49-711-970 1007 \\ E-mail: matthias.burgard@ipa.fraunhofer.de
}

Suggested Topic: • Parts sorting and feeding 


\title{
Feeding of Small Components Using the Surface Tension of Fluids
}

\begin{abstract}
The feeding of components smaller than $1 \mathrm{~mm}^{2}$ is a high challenge in an automated manufacturing line. The surface forces affecting these micro components are getting more important and cause problems when handled. A new method is described using the surface forces for separating, sorting and arranging micro components. The surface shape of fluids and the gravity are used for moving the floating components to defined positions. The components can be arranged in a magazine or can be sorted by a channel system.
\end{abstract}

Keywords: micro, sorting, feeding, arranging, handling, fluid, surface force, surface tension

\section{Introduction}

Due to the ongoing miniaturization of products and the simultaneously increasing scale of integration, the components to be handled are getting smaller. In contrast, the micro components and the assembly processes are continuously getting more sensitive towards the environment. As a result of this trend, the common vibratory conveyor technology reaches its limits due to its impact to the components and the occurring surface effects. In these cases, the separation and the arranging in a defined order for a further manual or automatic processing, for instance gripping of the component in the assembly process, is limited or even impossible.

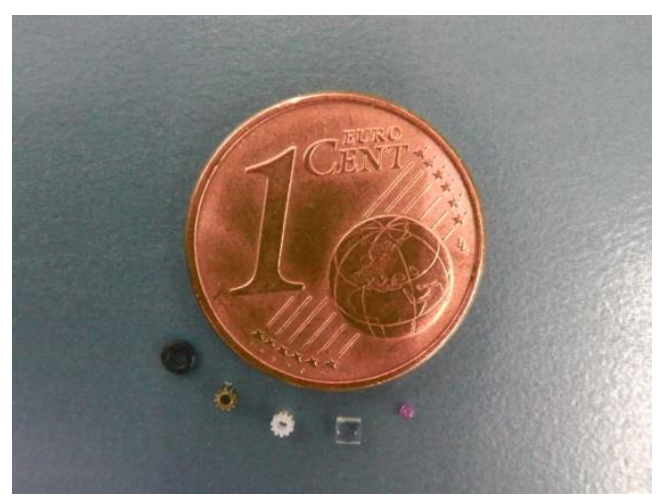

Fig. 1. Tested miniaturized components

In [1]-[3] new processes are described using surface tension for the assembly of micro parts. It has the big advantage that the surface forces are controlled and positively used for the process. In contrast the feeding of the micro components is still a conventional process with all its disadvantages for the handling of the small parts. 


\section{Approach}

The fluidic sorting technology described here is an approach adapted for components smaller than $1 \mathrm{~mm}$ which are provided as bulk good as for instance gear wheels, optical components, coated o-rings or electronic components (see figure 1). The fluidic sorting is based on the phenomenon to be found in nature that water striders can stay and glide on the water surface due to the surface tension. If small and therefore lightweight components are applied on a surface of a fluid, it shows similar behavior. In case of a concave or convex curve, the components are sliding to lower level to the fluid rim or to a present barrier.

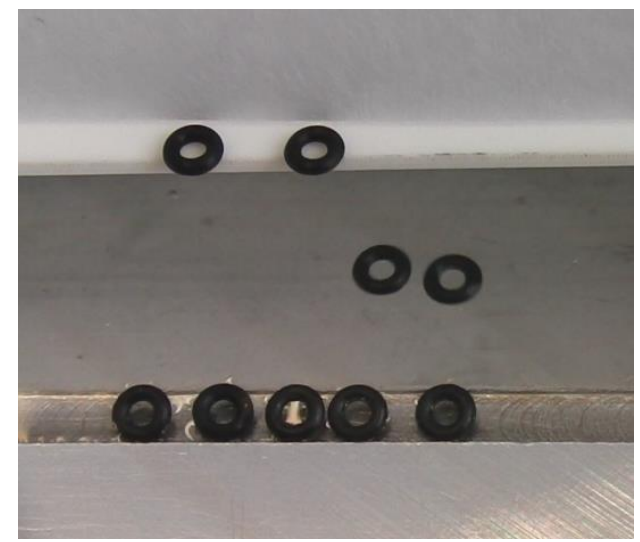

Fig. 2. Sliding o-rings on a convex fluidic surface

\section{$3 \quad$ Functionality and Set-up}

A defined formed fluidic surface is required for the process. To provide this, the fluidic sorting device features a reservoir which is incorporated into a base plate (see figure 3). The reservoir is filled with fluid and the required surface curvature is set by the filling level of the reservoir. After the reservoir is filled, the components will be applied onto the fluid. Due to the gravity, the components are moving to the rim of the fluid, which is defined by the geometry of the encircled incorporated structure. An agglomeration of components can be split up by a defined vibration. As soon as all components are arranged, the level of the fluid is lowered. A barrier is included in the reservoir rim, which can be overflown by the fluid but prevents the components to float back with the sucked fluid. In this manner an arrangement is achieved to enable an extraction of the components for instance with tweezers or with a pick-and-place system. 

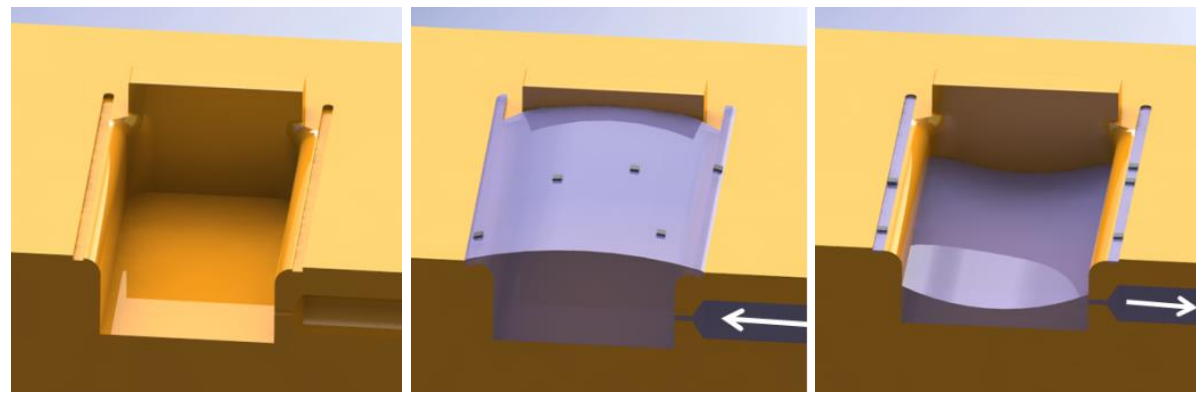

Fig. 3. Principle of the fluidic sorting process.

The set-up consists of four significant components:

1. the fluidic sorting device,

2. the fluid supply unit,

3. the collector module and

4. a vibration unit.
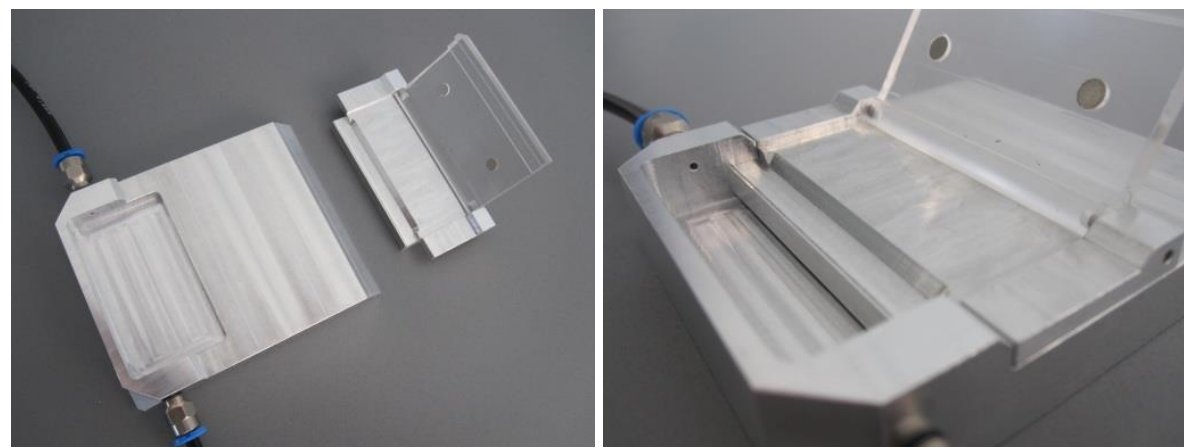

Fig. 4. Set-up with fluidic sorting device, collector module and interfaces to the fluid supply unit

The fluidic sorting device contains the reservoir. With the connected pump and valve system of the fluid supply unit, the reservoir can be filled and drained. An essential element of the set-up is the collector module for the capture of the processed components. It can be inserted into the fluidic sorting device. The width and depth of the incorporated structure is adapted to the components and it can have additional cavities for the separated arranging of the components. In the case of a further external processing, the collector module can be designed as a magazine. The collector module can be closed with an adapted cover element and airflow can be passed through the channel, realized by closing the cover, to dry the components. Also alcohol or ultrapure water can be used for cleaning or to reduce the risk of residues or particle contamination. The whole set-up is located on a vibration unit. With defined frequency, it is possible to split up an agglomeration and to arrange the components in a row. 


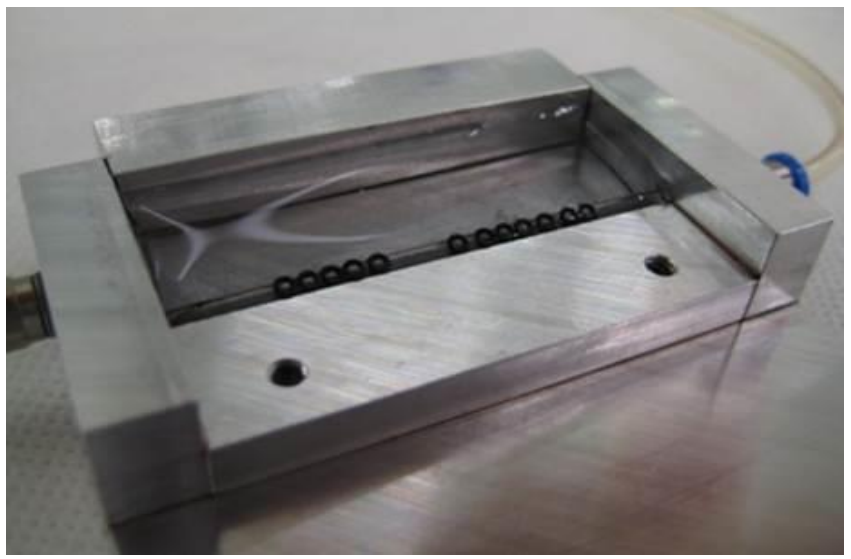

Fig. 5. Arranged components in a row after vibration

Components that where positively tested already are shown in figure 1. Not only the shape and dimensions of the micro components are manifold, also the material. Brass, glass, sapphire, silicone and various polymers (e.g. silicone) can be processed.

\section{Conclusion and Outlook}

A new process for separating, arranging and feeding micro components has been described using the surface tension for a gentle handling. A parallel processing of multiple parts is feasible with this method. Micro components made of various materials and many shapes can been processed with this method. A test platform has been realized including set-up and the control. In future tests, the process will be characterized in respect to e.g. reliability, failure ratio or throughput.

\section{$5 \quad$ References}

1. Burgard, Matthias ; Schläfli, Norbert ; Mai, Uwe: Processes for the Self-assembly of Micro Parts In: Ratchev, Svetan (Ed.) ; Westkämper, Engelbert (International Advisory Committee) ; u.a. ; IFIP / TC5 / WG 5.5: Precision Assembly Technologies and Systems : 6th IFIP WG 5.5 International Precision Assembly Seminar, IPAS 2012, Chamonix, France, February 12-15, 2012. Proceedings. Heidelberg u.a. : Springer, 2012, S. 36-41. (IFIP Advances in Information and Communication Technology 371).- DOI 10.1007/9783-642-28163-1 5

2. Burgard, Matthias ; Mai, Uwe ; Verl, Alexander: Automatisierte Bestückung von LEDs basierend auf Self-Assembly In: Bundesminister für Bildung und Forschung: MikroSystemTechnik Kongress 2011: 10. bis 12. Oktober 2011 in Darmstadt. Proceedings. Berlin; Offenbach : VDE Verlag, 2011, S. 559-561. - URN urn:nbn:de:0011-n-1834644

3. Burgard, Matthias: Self-Assembly - ein neuartiger Ansatz für die automatisierte Mikromontage In: Schlenker, Dirk (Tagungsleitung) ; Zeitschrift Mikroproduktion: mikroMon- 
tage : Prozesstechnik, Anlagentechnik. Fachtagung, 10. und 11. Mai 2011 in Stuttgart. München; Wien : Hanser, 2011, 22 Folien. - URN urn:nbn:de:0011-n-1850017

4. Schlenker, Dirk ; Othman, Nabih: Vereinzeln und Zuführen mikrotechnischer Bauteile In: Mikroproduktion. (2013), Nr. 2, S. 10-13.

5. Burgard, Matthias ; Othman, Nabih ; Frei, Marcus: Neue Herausforderungen an die Montagetechnik In: MicroMountains: 5. iNNOVATION fORUM für Mikrotechnik : 27. Februar 2013, Villingen-Schwenningen. Villingen-Schwenningen, 2013, 11 Folien.

6. Othman, Nabih: IPA.FluidSort - Separation of smallest components In: MicroMountains: 5. iNNOVATION fORUM für Mikrotechnik : 27. Februar 2013, Villingen-Schwenningen. Villingen-Schwenningen, 2013, Poster, 1 S. 